\title{
Very-High-Speed Miniaturized Permanent Magnet Motors: Design and Optimization
}

\author{
Guillaume Burnand and Yves Perriard, Senior IEEE \\ Integrated Actuators Laboratory (LAI) \\ École Polytechnique Fédérale de Lausanne (EPFL) \\ Switzerland \\ guillaume.burnand@epfl.ch
}

\begin{abstract}
This paper aims to present an optimization method for very-high-speed electrical machines based on multiphysical analytical models. Analytical models allow a fast design but have to be robust and reliable. The set of models presented is very complete and covers the mechanical design of the rotor, the computation of the losses and the computation of the back EMF and torque constants. All the models have been validated on a $400 \mathrm{krpm}$ prototype, which is, to the authors' knowledge, one of the smallest and fastest electrical motor ever operated. Several optimization scenarios are presented and analyzed to get the best performance of very-high-speed machines.

Index Terms - Very-high-speed motor, synchronous motor, miniaturized motor, permanent magnet, losses modeling, heuristic optimization.
\end{abstract}

\section{INTRODUCTION}

Very-high-speed (VHS) applications are used in research and industry, such as pumps, fans, gas turbines, turbochargers, compressors, machine tools, drills for dental and medical applications or even flywheels for energy storage [1], [2]. Indeed, by increasing the rotational speed of electrical machines, for a given power, the size of the machine can be diminished, miniaturizing the device, increasing its power density and lowering its weight.

However, the drawback is the creation of losses related to very-high speed that are usually negligible in low-speed machines. One of the most important challenges when designing VHS machines is the minimization of these losses. Hence, the determination of accurate and reliable losses models is essential. The other important aspects to consider are mainly the rotor mechanical strength, the bearings and the heating.

A one-half inch diameter $400 \mathrm{krpm}$ miniaturized permanent magnet (PM) motor has been designed and built as pictured in Fig. 1. To the authors' knowledge it is one of the smallest and fastest electrical motor ever operated. Typical applications for such a motor are for medical and dental surgery or for micro gas turbines. A slotless structure has been chosen mainly because this reduces the induced rotor losses, as there are no slotting harmonics. All the models used in this paper have been validated and/or obtained by regression thanks to measurements on this motor [3]. Subsequently, an optimization can be carried out to minimize the total losses and give the optimal dimensions of the motor under some constraints.

Electrical motors represent a large field of application for optimization. Today's focus on the maximization of the efficiency of motors, but also on cost reduction, volume and/or weight limitation, justifies optimization. Furthermore, electrical machines are inherently multiphysical. They combine electromagnetic, mechanical and thermal properties. Mixing several physical models results in antagonistic outcomes. For instance, reducing the radius of the permanent magnet increases its mechanical strength to the rotational speed but decreases the electromagnetic torque. The optimization allows to find a suitable compromise when there are a lot of variables to handle.

There are at least two different approaches when performing multiphysics system optimization: using finite element methods (FEM) [4], [5] or fully analytical models [6], [7]. The first ones can solve non-trivial geometries and structures but require long computation time. Whereas the second ones are very fast, but are not always conform to reality because of simplifying assumptions. However, analytical models are preferred during pre-design to obtain fast estimations or to obtain inputs for FEM models. One can even consider a combination of the two approaches [8].

In electrical machines optimization, both iterative methods, such as sequential quadratic programming (SQP) [9] and heuristic methods, such as genetic algorithm (GA) [7], [10], [11], Nelder-Mead simplex method [6], ant colony algorithm [12] or particle swarm optimization [13], are used. One can also note the combination of FEM and metamodels [5].

More specifically, for VHS machines, a $500 \mathrm{krpm} 100 \mathrm{~W}$ PM synchronous motor has been optimized in [6] . Similarly, the optimization of a $200 \mathrm{krpm} 2 \mathrm{~kW}$ PM synchronous motor has been investigated in [7].

Although GA offers no guarantee of finding a true optimum, it does not need the initialization of variables (initial guess) and it presents less risk of finding a local optimum, as its search space is broader than iterative methods [11]. These are the main reasons why GA is widely used in electrical motor optimization [10].

Section II presents the different analytical models used for the optimization. These models allow the computation of the back EMF voltage, the electrical and mechanical losses and the mechanical stresses in the rotor. The optimization takes place in Section III, where the variables, the constraints and the chosen optimization algorithm are detailed. Finally, 4 optimization scenarios are presented and discussed in Section IV. 


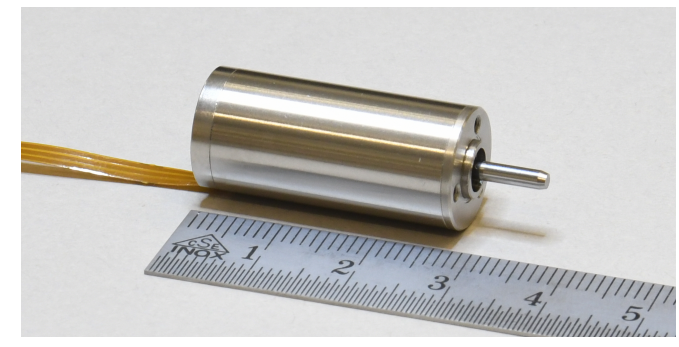

Fig. 1: The one-half inch diameter prototype used to validate the models in [3].

\section{MOTOR MODELING}

\section{A. Back EMF and torque constant}

For a one pole pair diametrically magnetized cylindrical PM slotless machine, the axial component of the vector potential in the airgap, in cylindrical coordinates, can be computed as [14]

$$
A_{\delta z}(r, \varphi)=c_{\delta}\left(r+\frac{r_{y i}^{2}}{r}\right) \sin (\varphi-\theta),
$$

with $\theta$ being the mechanical angle of the rotor and

$$
c_{\delta}=\frac{B_{r} r_{m o}^{2}\left(r_{m i}^{2}-r_{m o}^{2}\right)}{\mu_{r}\left(r_{m i}^{2}+r_{m o}^{2}\right)\left(r_{m o}^{2}-r_{y i}^{2}\right)+\left(r_{m i}^{2}-r_{m o}^{2}\right)\left(r_{m o}^{2}+r_{y i}^{2}\right)},
$$

is a constant depending on the geometry (see Fig. 2) and the properties of the PM. $B_{r}$ and $\mu_{r}$ are respectively the PM remanence and permeability.

The winding is illustrated in Fig. 3. It consists of a 3-phase delta-connection winding made of rectangular section wires. With $\Gamma$ being the path in the center of the wire, considering a purely sinusoidal magnetic flux density in the airgap as given by (1) and the mechanical angle of the rotor $\theta$ maximizing the flux linkage in the coil, the back EMF constant is worth

$$
k_{e}=\frac{\sqrt{2}}{2} \oint_{\partial \Gamma} \vec{A} \cdot \overrightarrow{\mathrm{d} l} .
$$

Given the geometry of the coils and, assuming that the straight parts of the winding have the same axial length than the permanent magnet, the back EMF constant for this winding can be computed as

$$
k_{e}=\frac{\sqrt{2}}{2} \sum_{n=1}^{N_{t}} A\left(\bar{r}_{w}, \varphi_{n}\right) L_{\mathrm{PM}},
$$

where $L_{\mathrm{PM}}$ is the axial length of the PM and $\bar{r}_{w}$ is the mean radius of wires given by

$$
\bar{r}_{w}=\frac{r_{w i}+r_{w o}}{2} .
$$

For 3-phase delta-connected windings, the torque constant $k_{T}$ is equal to the back EMF constant $k_{e}$ [15].

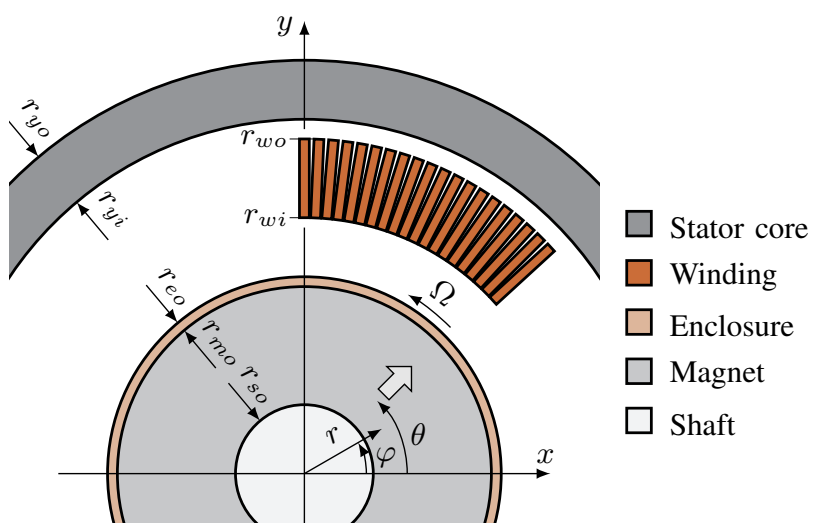

Fig. 2: Cross-section of the motor with half a coil of one phase highlighted and its dimensions.

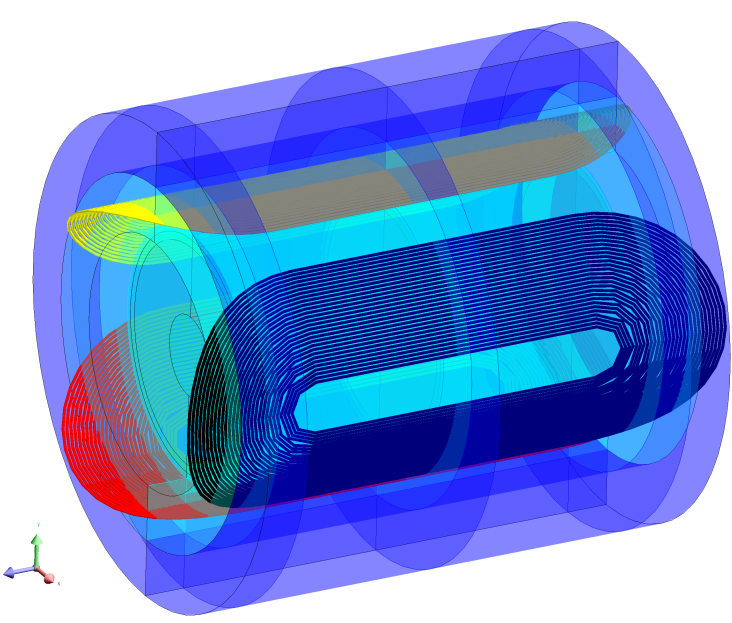

Fig. 3: 3D view of the winding highlighting the paths in the center of the wires.

\section{B. Windage losses}

Windage losses represent a non-negligible part of the total losses in very-high-speed machines because they have the highest rate of increase with respect to rotational speed. There are many empirical models to assess them [16]-[18], but it is sometimes complicated to know which one to choose. Besides, they all give different evaluations. Windage losses can be computed, for a cylindrical rotor spinning in a coaxial stator (slotless machine), according to

$$
P_{\text {Windage }}=\pi c_{f} \rho \Omega^{3} r_{e o}^{4} L_{\delta},
$$

where $\rho$ is the density of the fluid in the airgap, $\Omega$ the rotational speed, $L_{\delta}$ the axial length of the airgap and $c_{f}$ the friction coefficient. The friction coefficient given by Mack's model [19] has been experimentally validated in [3], [20], [21] and is used during the optimization process. 


\section{Ball bearing losses}

For ball bearings running at moderate speeds, some empirical formulae based on laboratory testing are available [22]. In these formulae, the total friction torque is evaluated as the sum of a torque due to the applied load and a torque due to the viscous property of the lubricant. However, for very-highspeed applications, ball bearing losses are most of the time measured [7]. These losses can be modeled empirically by

$$
P_{\text {Bearings }}=c_{\text {Bearings } 1} \Omega^{c_{\text {Bearings } 2}},
$$

where $\Omega$ is the mechanical speed of the rotor in $\mathrm{rad} / \mathrm{s}$ and $c_{\text {Bearings1 }}$ and $c_{\text {Bearings2 }}$ are coefficients obtained by regression.

\section{Iron losses}

Iron losses are created by a time-varying magnetic field due to the currents in the winding and the rotation of the permanent magnet. The last one is much more important in PM slotless machines. According to Jordan's model [23], iron losses due to the PM sinusoidal field can be split into hysteresis and eddy current losses. The losses are then empirically modeled by

$$
P_{\mathrm{IronPM}}=\pi\left(r_{y o}^{2}-r_{y i}^{2}\right) L_{\mathrm{PM}} k_{f}\left(c_{\mathrm{Iron} 1} \Omega \hat{B}_{y}^{2}+c_{\mathrm{Iron} 2} \Omega^{2} \hat{B}_{y}^{2}\right),
$$

where $L_{\mathrm{PM}}$ is the axial length of the PM (assumed to be shorter than the axial length of the stator), $k_{f}$ is the stacking factor, $c_{\text {Iron1 }}$ and $c_{\text {Iron2 }}$ are coefficients obtained by regression and $\hat{B}_{y}$ is the peak magnetic flux density in the stator yoke given by [24]

$$
\hat{B}_{y}=\frac{2 c_{\delta}}{k_{f}} \frac{\left(r_{y o}^{2}+r_{y i}^{2}\right)}{\left(r_{y o}^{2}-r_{y i}^{2}\right)} .
$$

Low losses amorphous iron-based alloy Metglas ${ }^{\circledR}$ 2605SA1 is chosen for the stator in the optimization.

\section{E. Winding losses}

Winding losses are created by the circulation of the current in the stator winding and their time-variation. This gives 3 components: the Joule losses, the skin effect losses, which concentrate the current density on the outer border of the wires, and the proximity effect losses, resulting from perturbation in between each wire of the winding. The last two components are especially happening when the stator electrical frequency is high. In the case of slotless permanent magnet machines, winding losses have an additional component due to eddy current losses caused by the time-variation of the PM field.

Nonetheless, the magnetic flux density in the airgap is overwhelmingly due to the permanent magnet itself in slotless machines. As a result, proximity effect losses can be most of the time neglected because the magnetic flux density created by the currents flowing in the winding is low in comparison [18]. As for skin effect losses, they are not considered for the sake of simplicity.

Thus, Joule losses are given by

$$
P_{\text {Joule }}=3 \rho_{w} h_{w} w_{w} J^{2}\left(2 N_{t} L_{\mathrm{PM}}+\pi \bar{r}_{w} \sum_{n=1}^{N_{t}} \alpha_{n}\right)
$$

where $\rho_{w}$ is the resistivity of the wire, $h_{w}$ and $w_{w}$ are respectively the height and the width of a wire and the $\alpha_{n}$ are the end-winding opening angles of each turn.

An analytical model for the computation of induced eddy current losses in the winding due to the PM field is developed in [3]. The model considers a single rectangular section wire, computes the induced current density all over its surface $S_{w}$ and then integrates this current density over a time period $T$. Thereby, the power loss per unit length for one coil of $N_{t}$ turns is computed by the following integration

$$
P_{\text {WindingPM }}^{\prime}=\frac{2 \rho_{w} N_{t}}{T} \int_{0}^{T} \int_{S_{w}} J_{z}^{2}(x, y, t) \mathrm{d} S \mathrm{~d} t .
$$

\section{F. Rotor losses}

Rotor losses are due to eddy currents induced by the stator magnetic field in the enclosure, the permanent magnet and possibly the shaft. These losses are usually insignificant compared to the total losses in slotless machines [18]. However, in some cases, it is important to evaluate them since the losses produced in the rotor are not easy to dissipate. Excessive temperature in the rotor would reduce the performance of the magnet and limit the mechanical strength of materials.

The rotor losses can be computed analytically [25] or by FEM [26]. However, as demonstrated experimentally in [3], rotor losses are negligible in miniaturized slotless machines and hence are not modeled here.

\section{G. Rotor mechanical strength}

Centrifugal forces induce significant stresses in the rotor materials that can be destructive. In VHS machines, it is common to surround the permanent magnet into a retaining enclosure. Indeed, rare earth magnets have a good compressive strength, but a weak ultimate tensile strength. The enclosure is mounted with an interference, inducing a compressive stress on the magnet. The equations to compute the mechanical stresses in the rotor can be found in [27]. For the following optimization, the chosen material for the enclosure is titanium grade 5, the magnet is $\mathrm{NdFeB}$ and the shaft is stainless steel.

\section{H. Power balance}

In order to get the mechanical power provided by the motor as a constraint during the optimization, a power balance has to be done. The sum of all losses in the motor is assumed to be

$$
\Sigma P=P_{\text {Windage }}+P_{\text {Bearings }}+P_{\text {IronPM }}+P_{\text {WindingPM }}+P_{\text {Joule }} .
$$

Then, the mechanical power can be computed, knowing the motor torque constant $k_{T}$ (deduced from (4)), the phase current $I_{p h}$ and the mechanical speed of the rotor $\Omega$, by

$$
\begin{aligned}
P_{\text {mec }}= & 3 k_{T} I_{p h} \Omega- \\
& \left(P_{\text {Windage }}+P_{\text {Bearings }}+P_{\text {IronPM }}+P_{\text {WindingPM }}\right) .
\end{aligned}
$$




\section{OPTIMIZATION}

An optimization process is almost inevitable in motor design, especially for VHS motors. For example, to reduce windage losses, the outer radius of the enclosure should be as small as possible. But doing so will also diminish the electromagnetic torque because of a smaller magnet. This is a simple example of antagonistic objectives. Besides, the number of variables can easily reach a dozen or more. A global and multiphysical optimization using robust and reliable models is then required.

\section{A. Objective function}

As previously mentioned, the minimization of losses in VHS machines is one of the most important challenges. Hence, the objective function to minimize is the sum of losses $\Sigma P$ given by (12). It is a mono-objective function and, as a result, Pareto frontiers cannot be visualized. Thermal modeling is not considered here. However, the minimization of losses is consistent with the reduction of heating.

\section{B. Design variables}

The number of turns per coil $N_{t}$ is chosen as a variable. This has the advantage of perfectly matching the winding as it will be, instead of assuming an hypothetical coil filling factor. Thus, the optimization algorithm must be able to deal with integer numbers. This is one of the reasons why GA is chosen.

Other variables are the permanent magnet remanence $B_{r}$, the phase current density $J$ and all the dimensions of the motor (see TABLE IV), leading to a total of 12 variables. The permanent magnet remanence $B_{r}$ has a great influence on electromagnetic losses because the magnetic flux density in slotless machine is predominantly due to the PM itself. Thus, there is a compromise to be found between the electromagnetic torque (high $B_{r}$ ) and the losses (low $B_{r}$ ). The same applies to the current density $J$.

The values of the constants for the model of ball bearing losses (7) and the model of iron losses due to the PM field (8) are given in TABLE I. They have been established experimentally in [3].

\section{Constraints and fixed parameters}

There are linear constraints on the maximal peak magnetic flux density in the stator yoke and the minimal thickness of the enclosure around the magnet. The maximal peak magnetic flux density has to be lower than the magnetic saturation of the stator material. The minimal thickness of the enclosure has been set to $0.2 \mathrm{~mm}$, because a lower thickness would be difficult to manufacture. The maximal current density, the maximal PM axial length and the outer diameter of the motor are constrained by upper boundaries.

Non-linear constraints are set on the mechanical power $P_{\text {mec }}$ given by (13), the rotor mechanical strength and the maximal back EMF voltage. The maximal back EMF voltage has been set below $50 \mathrm{~V}$ to stay in the very low voltage range. The nominal speed of the motor has been set to $400 \mathrm{krpm}$, but the rotor is designed to sustain a rotational speed of $500 \mathrm{krpm}$.
The rest of the constraints and fixed parameters for the optimization is visible in TABLE II. The temperature of the motor has been assumed to be at $60{ }^{\circ} \mathrm{C}$ because it is a common temperature for medical hand tools.

The modal analysis, to avoid critical speeds lying near the operating speed range, and the thermal behaviour of the motor are not considered in the optimization. Critical speeds can be further computed or added in the optimization loop thanks to 1D FEM [28] or 3D FEM commercial software for more complex geometries. And the minimization of losses is consistent with the limitation of temperature in the motor.

\section{Optimization algorithm}

The optimization is performed using the genetic algorithm of the MATLAB function $g a$. This allows to deal with an integer, which is the number of turns per coil $N_{t}$. Besides, for such a number of variables, GA is more appropriated than iterative methods. Furthermore, GA is preferred for the windage losses model (6), which is discontinuous (Mack's model), and the model for winding losses due to the PM field (11), which does not have an analytical solution and must be computed numerically. Finally, GA does not require an initial guess to start the optimization and is less liable to find a local optimum. The parameters of the algorithm are given in TABLE III.

TABLE I: LOSSES MODELS CONSTANTS

\begin{tabular}{|c|c|}
\hline \multicolumn{2}{|c|}{ Ball bearing losses } \\
\hline$c_{\text {Bearings1 }}$ & $26.677 \times 10^{-12}$ \\
\hline$c_{\text {Bearings2 }}$ & 2.380 \\
\hline \multicolumn{2}{|c|}{ Iron losses due to the PM } \\
\hline$c_{\text {Iron } 1}$ & 11.415 \\
\hline$c_{\text {Iron2 }}$ & $1.110 \times 10^{-3}$ \\
\hline
\end{tabular}

TABLE II: FIXED PARAMETERS AND CONSTRAINTS

\begin{tabular}{lccc}
\hline Motor temperature & $T_{\mathrm{mot}}$ & 60 & {$\left[{ }^{\circ} \mathrm{C}\right]$} \\
PM permeability & $\mu_{r}$ & 1.05 & {$[-]$} \\
Wire resistivity & $\rho_{w}$ & $20.0 \times 10^{-9}$ & {$[\Omega \mathrm{m}]$} \\
Wire insulation & $e_{w}$ & 10 & {$[\mu \mathrm{m}]$} \\
Stator stacking factor & $k_{f}$ & 0.82 & {$[-]$} \\
Stator material saturation & $B_{\mathrm{sat}}$ & 1.56 & {$[\mathrm{~T}]$} \\
Nominal rotational speed & $N$ & 400 & {$[\mathrm{krpm}]$} \\
Maximal rotational speed & $N_{\max }$ & 500 & {$[\mathrm{krpm}]$} \\
Max back EMF voltage & $U_{\text {ind } \max }$ & 50 & {$[\mathrm{~V}]$} \\
\hline
\end{tabular}

TABLE III: GENETIC ALGORITHM PARAMETERS

\begin{tabular}{ll}
\hline Maximal iterations & 1200 \\
Maximal stall generations & 50 \\
Population size & 200 \\
Non-linear constraint algorithm & Augmented Lagrange \\
Crossover fraction & 0.8 \\
Crossover function & Scattered \\
Elite count & 10 \\
\hline
\end{tabular}




\section{Results}

In the following optimizations, ball bearing losses are assumed to be independent from all other variables.

\section{A. $40 \mathrm{~W}$ motor}

The first optimization, called OPT 1 , has been carried out with a mechanical power of $40 \mathrm{~W}$, a maximal PM axial length of $15 \mathrm{~mm}$, a maximal outer motor diameter of $12.7 \mathrm{~mm}$ (the maximal outer radius of the stator yoke $r_{y o}$ is set to $6 \mathrm{~mm}$ to allow space for the housing of the motor) and a maximal current density of $10 \mathrm{~A} / \mathrm{mm}^{2}$. The results are presented in TABLE IV. One notes that both the PM axial length and the outer motor diameter have been set to their maximal authorized values. In other words, the maximal available volume is filled. The sum of losses is $10.3 \mathrm{~W}$, giving an efficiency of $79.3 \%$. One of the biggest shares is the winding losses due to the PM field (see Fig. 4).

In order to reduce the aforementioned losses, the maximal current density is increased to $30 \mathrm{~A} / \mathrm{mm}^{2}$. This gives OPT 2 . The main changes have been highlighted with colors in TABLE IV. The efficiency has been significantly increased to
84.4\%. The PM axial length has been decreased to almost 11 $\mathrm{mm}$, diminishing the volume and increasing the power density. The radius of the rotor has been decreased, allowing more space for the stator yoke and the airgap.

Indeed, the winding losses due to the PM field have been drastically reduced to $0.50 \mathrm{~W}$. This can be explained by 2 aspects. First, the radial thickness of the permanent magnet has been slightly reduced, leading to less magnetic flux density in the airgap. Second, and as a consequence of the latter, the number of turns is increased, reducing the width of the wire. As a result of the drop of the magnetic flux density in the airgap, the current density has been increased to provide the requested torque. This is why Joule losses have more than doubled to reach $1.97 \mathrm{~W}$. This can be visualised in Fig. 4, where Joule losses have become an important part of the total losses $(27 \%)$.

As a consequence of the diminution of the magnetic flux density in the motor and the increase of the stator yoke thickness, the peak magnetic flux density in the stator yoke has been decreased. In this way, iron losses due to the PM field have greatly dropped to $0.87 \mathrm{~W}$.

TABLE IV: OPTIMIZATION RESULTS

\begin{tabular}{|c|c|c|c|c|c|c|}
\hline & & OPT 1 & OPT 2 & OPT 3 & OPT 4 & \\
\hline \multicolumn{7}{|l|}{ Constraints } \\
\hline Mechanical power & $P_{\text {mec }}$ & 40 & 40 & 100 & 100 & {$[\mathrm{~W}]$} \\
\hline Maximal PM axial length & $L_{\mathrm{PM} \max }$ & 15 & 15 & 15 & 15 & {$[\mathrm{~mm}]$} \\
\hline Maximal outer diameter & $d_{\text {mot } \max }$ & 12.7 & 12.7 & 12.7 & 16 & {$[\mathrm{~mm}]$} \\
\hline Maximal current density & $J_{\max }$ & 10 & 30 & 30 & 30 & {$\left[\mathrm{~A} / \mathrm{mm}^{2}\right]$} \\
\hline \multicolumn{7}{|l|}{ Design variables } \\
\hline Number of turns & $N_{t}$ & 34 & 40 & 38 & 37 & {$[-]$} \\
\hline PM remanence & $B_{r}$ & 1.16 & 1.14 & 1.19 & 1.38 & {$[\mathrm{~T}]$} \\
\hline PM axial length & $L_{\mathrm{PM}}$ & 15.0 & 11.1 & 14.1 & 14.7 & {$[\mathrm{~mm}]$} \\
\hline Outer shaft radius & $r_{\text {so }}$ & 1.35 & 1.00 & 1.18 & 1.07 & {$[\mathrm{~mm}]$} \\
\hline Outer magnet radius & $r_{m o}$ & 2.52 & 2.11 & 2.48 & 2.19 & {$[\mathrm{~mm}]$} \\
\hline Magnet-enclosure interference & $e_{0}$ & 7.6 & 5.6 & 6.76 & 4.6 & {$[\mu \mathrm{m}]$} \\
\hline Outer enclosure radius & $r_{e o}$ & 2.72 & 2.31 & 2.70 & 2.47 & {$[\mathrm{~mm}]$} \\
\hline Inner wire radius & $r_{w i}$ & 3.54 & 3.30 & 3.25 & 3.47 & {$[\mathrm{~mm}]$} \\
\hline Outer wire radius & $r_{w o}$ & 4.50 & 4.10 & 4.02 & 4.36 & {$[\mathrm{~mm}]$} \\
\hline Inner yoke radius & $r_{y i}$ & 4.60 & 4.20 & 4.12 & 4.46 & {$[\mathrm{~mm}]$} \\
\hline Outer yoke radius & $r_{y o}$ & 6.00 & 6.00 & 6.00 & 7.61 & {$[\mathrm{~mm}]$} \\
\hline Phase current density & $J$ & 10.0 & 18.8 & 28.4 & 26.1 & {$\left[\mathrm{~A} / \mathrm{mm}^{2}\right]$} \\
\hline \multicolumn{7}{|l|}{ Derived quantities } \\
\hline Wire width & $w_{w}$ & 83 & 61 & 64 & 72 & {$[\mu \mathrm{m}]$} \\
\hline Wire height & $h_{w}$ & 0.96 & 0.80 & 0.77 & 0.88 & {$[\mathrm{~mm}]$} \\
\hline Back EMF voltage & $U_{\text {ind }}$ & 20.6 & 14.4 & 26.1 & 21.3 & [V] \\
\hline Stator peak flux density & $\hat{B}_{y}$ & 1.25 & 0.82 & 1.21 & 0.66 & {$[\mathrm{~T}]$} \\
\hline Mechanical airgap & $\delta$ & 0.82 & 0.98 & 0.55 & 1.00 & {$[\mathrm{~mm}]$} \\
\hline Sum of losses & $\Sigma P$ & 10.3 & 7.31 & 12.5 & 11.9 & {$[\mathrm{~W}]$} \\
\hline Ball bearing losses & $P_{\text {Bearings }}$ & 2.69 & 2.69 & 2.69 & 2.69 & {$[\mathrm{~W}]$} \\
\hline Windage losses & $P_{\text {Windage }}$ & 2.60 & 1.29 & 2.19 & 1.99 & {$[\mathrm{~W}]$} \\
\hline Iron losses due to PM & $P_{\text {IronPM }}$ & 2.17 & 0.87 & 2.47 & 1.52 & {$[\mathrm{~W}]$} \\
\hline Winding losses due to PM & $P_{\text {WindingPM }}$ & 2.15 & 0.50 & 1.36 & 1.42 & {$[\mathrm{~W}]$} \\
\hline Joule losses & $P_{\text {Joule }}$ & 0.74 & 1.97 & 3.78 & 4.34 & {$[\mathrm{~W}]$} \\
\hline Motor efficiency & $\eta$ & 79.3 & 84.4 & 88.9 & 89.3 & {$[\%]$} \\
\hline
\end{tabular}




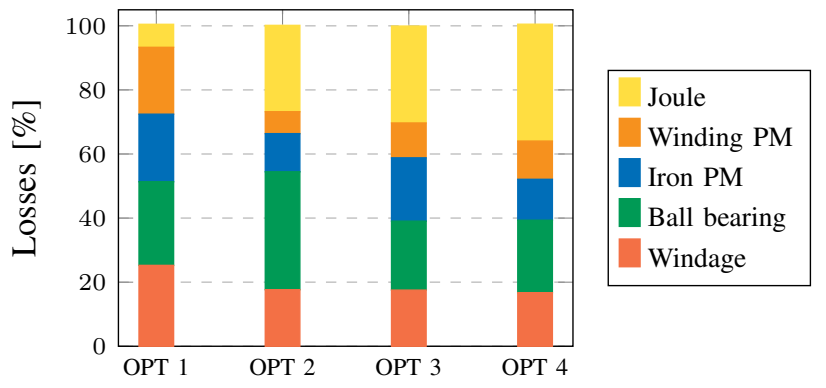

Fig. 4: Distribution of losses.

One has to keep in mind that VHS machines do not require a high torque and, therefore, a high magnetic flux density in the airgap. Their power comes mainly from their speed. Increasing the current density seems counterintuitive, but it increases the efficiency of the motor by allowing a better balance between Joule losses on the one hand and iron and winding losses due to the PM field on the other hand. Indeed, induced losses (iron and winding) due to the rotation of the PM scale with the square of both magnetic flux density and rotational speed. Given that the first one in VHS machines is extremely high anyway, one can only act on the second one.

The windage losses have been halved due to the reduction of the axial length of the motor, but mostly thanks to the reduction of the radius of the rotor. Indeed, as given in (6), these losses scale with the outer radius of the enclosure to the power 4.

\section{B. $100 \mathrm{~W}$ motor}

OPT 3 deals with a mechanical power of $100 \mathrm{~W}$ and the same maximal outer dimensions. The result is that Joule losses have become important and represent $30 \%$ as visible in Fig. 4. The efficiency is $88.9 \%$, but it should not be compared with the other optimizations because the mechanical power is different.

Given that OPT 3 has reached the maximal outer dimensions of the motor, OPT 4 will set the limit of the diameter to $16 \mathrm{~mm}$ ( $r_{y o} \max$ is set to $7.65 \mathrm{~mm}$ ). It turns out that the optimization has increased the diameter of the motor almost to its maximal value to lower the total losses. The efficiency is now $89.3 \%$.

More space is now available for the stator yoke, halving the peak magnetic flux density and thereby the iron losses. The same applies to the airgap, decreasing the windage losses.

The radial dimensions of the rotor have been decreased and the remanence of the PM has been increased to compensate the increase of the airgap.

Increasing the outer diameter of the motor increases the efficiency (to some extend) of the motor for a given mechanical power. This has already been noticed in [6]. This fact can be explained by a better use of the available space in order to reduce the losses. Furthermore, the bigger the diameter of the machine, the better thermal convection, because the exchange surface is bigger. This demonstrates the difficulty of designing miniaturized motors.

\section{Synthesis}

The size of the rotor (radial dimensions) has fundamentally not been changed over the 4 optimizations. At $500 \mathrm{krpm}$ (maximal rotational speed used as a constraint for the design of the rotor) and with the given materials, the limit of the mechanical strength is reached. An increase of the diameter would lead to a mechanical failure. Furthermore, it drastically increases windage losses.

Indeed, windage losses represent an important part of the total losses for each optimization. They are between 15-25\% as it can be seen in Fig. 4. This is why a reliable and validated model has to be selected for the design of VHS machines.

Another interesting remark is that Joule and winding losses due to the PM field are antagonistic. Indeed, increasing the surface of the wire decreases the DC resistance, whereas it enables more induced eddy currents to flow.

The value of the peak magnetic flux density in the stator yoke seems very low when compared to the saturation of $1.56 \mathrm{~T}$. It could be seen as a misuse of the iron capabilities. Yet, it should be seen as a way to decrease iron losses, which vary with the square of the peak magnetic flux density. All the aforementioned facts, plus the number of variables, make an optimization process inevitable when designing VHS machines.

\section{CONCLUSION}

An optimization method for very-high-speed electrical machines based on multiphysical analytical models has been presented. The set of the models presented is very complete and covers the mechanical design of the rotor, the computation of the losses and the computation of the back EMF and torque constants. All the models have been validated on a $400 \mathrm{krpm}$ prototype, which is, to the authors' knowledge, one of the smallest and fastest electrical motor ever operated.

Even though analytical models may lack accuracy in some circumstances, they are preferred (at least for pre-design) when there is an important number of variables in optimization, because of their fast computing capabilities.

Several optimization scenarios are presented. Results strongly depend on the mechanical power provided, the maximal dimensions and the maximal current density allowed. The modeling of each turns of the winding makes the design more accurate and closer to reality.

The paper shows that the miniaturization of VHS electrical machines is complicated because the losses do not decrease linearly with the size of the motor. Furthermore, losses related to very high speed become a very important part of the total losses and the reduced dimensions make it difficult to diminish these losses. As a consequence, the efficiency is generally lower than in low-speed machines. Nonetheless, VHS machines offer a higher power density leading to a reduction of the size and the weight.

A thermal model could be implemented to the optimization process for even more accuracy and also to consider forced cooling of the motor. However, reducing the losses in the machine is consistent with the limitation of temperature. 


\section{REFERENCES}

[1] D. Gerada, A. Mebarki, N. L. Brown, C. Gerada, A. Cavagnino, and A. Boglietti, "High-Speed Electrical Machines: Technologies, Trends, and Developments," IEEE Transactions on Industrial Electronics, vol. 61, pp. 2946-2959, June 2014.

[2] C. Zwyssig, J. Kolar, and S. Round, "Megaspeed Drive Systems: Pushing Beyond 1 Million r/min," IEEE/ASME Transactions on Mechatronics, vol. 14, pp. 564-574, Oct. 2009.

[3] G. Burnand and Y. Perriard, "Very-High-Speed Miniaturized Permanent Magnet Motors: Modeling and Experimental Validation," in IEEE Energy Conversion Congress and Exposition (ECCE), (Baltimore), pp. 1-7, IEEE, Oct. 2019.

[4] Wei Wu, J. Dunlop, S. Collocott, and B. Kalan, "Design optimization of a switched reluctance motor by electromagnetic and thermal finiteelement analysis," IEEE Transactions on Magnetics, vol. 39, pp. 3334 3336 , Sept. 2003.

[5] D.-K. Hong, T.-W. Lee, and Y.-H. Jeong, "Design and Experimental Validation of a High-Speed Electric Turbocharger Motor Considering Variation of the L/D Ratio," IEEE Transactions on Magnetics, vol. 54, pp. 1-4, Nov. 2018

[6] J. Luomi, C. Zwyssig, A. Looser, and J. Kolar, "Efficiency Optimization of a 100-W 500000-r/min Permanent-Magnet Machine Including AirFriction Losses," IEEE Transactions on Industry Applications, vol. 45, pp. 1368-1377, July 2009.

[7] P.-D. Pfister and Y. Perriard, "Very-high-speed slotless permanentmagnet motors: Analytical modeling, optimization, design, and torque measurement methods," IEEE Transactions on Industrial Electronics, vol. 57, pp. 296-303, Jan. 2010.

[8] J. Dong, Y. Huang, L. Jin, H. Lin, and H. Yang, "Thermal Optimization of a High-Speed Permanent Magnet Motor," IEEE Transactions on Magnetics, vol. 50, pp. 749-752, Feb. 2014.

[9] Y. Le and K. Wang, "Design and Optimization Method of Magnetic Bearing for High-Speed Motor Considering Eddy Current Effects," IEEE/ASME Transactions on Mechatronics, vol. 21, pp. 2061-2072, Aug. 2016.

[10] T. Raminosoa, B. Blunier, D. Fodorean, and A. Miraoui, "Design and Optimization of a Switched Reluctance Motor Driving a Compressor for a PEM Fuel-Cell System for Automotive Applications," IEEE Transactions on Industrial Electronics, vol. 57, pp. 2988-2997, Sept. 2010.

[11] Yun Le, Jiancheng Fang, and Kun Wang, "Design and Optimization of a Radial Magnetic Bearing for High-Speed Motor With Flexible Rotor," IEEE Transactions on Magnetics, vol. 51, pp. 1-13, June 2015.

[12] Y. Li, C. Zhu, L. Wu, and Y. Zheng, "Multi-Objective Optimal Design of High-Speed Surface-Mounted Permanent Magnet Synchronous Motor for Magnetically Levitated Flywheel Energy Storage System," IEEE Transactions on Magnetics, pp. 1-8, 2019.

[13] L. Liu, W. Liu, and D. A. Cartes, "Particle swarm optimizationbased parameter identification applied to permanent magnet synchronous motors," Engineering Applications of Artificial Intelligence, vol. 21, pp. 1092-1100, Oct. 2008.

[14] P. Ragot, Modélisation analytique multiphysique pour la conception optimale de moteurs synchrones à aimants permanents. $\mathrm{PhD}$ thesis, École Polytechnique Fédérale de Lausanne, Lausanne, 2008.

[15] F. Copt, D. M. Araujo, C. Koechli, and Y. Perriard, "Current Control Strategy for Dynamic Winding Reconfiguration of Slotless Brushless DC Motors," IEEE Transactions on Industry Applications, vol. 55, pp. 417425, Jan. 2019.

[16] J. Saari, Thermal analysis of high speed induction machines. $\mathrm{PhD}$ thesis, Helsinki University of Technology, Espoo, 1998.

[17] E. H. Maslen and G. Schweitzer, Magnetic Bearings. Berlin, Heidelberg: Springer Berlin Heidelberg, 2009.

[18] A. Borisavljevic, Limits, Modeling and Design of High-Speed Permanent Magnet Machines. Springer Theses, Berlin, Heidelberg: Springer Berlin Heidelberg, 2013

[19] M. Mack, Luftreibungsverluste bei elektrischen Maschinen kleiner Baugrössse. PhD thesis, Universität Stuttgart (FH), Stuttgart, 1967.

[20] J. Demierre, A. Rubino, and J. Schiffmann, "Modeling and Experimental Investigation of an Oil-Free Microcompressor-Turbine Unit for an Organic Rankine Cycle Driven Heat Pump," Journal of Engineering for Gas Turbines and Power, vol. 137, no. 3, p. 032602, 2015.
[21] G. Burnand, D. M. Araujo, C. Koechli, and Y. Perriard, "Validation by measurements of a windage losses model for very-high-speed machines," in 20th International Conference on Electrical Machines and Systems (ICEMS), pp. 1-4, IEEE, Aug. 2017.

[22] T. A. Harris and M. N. Kotzalas, Rolling bearing analysis - Essential concepts of bearing technology, vol. 1. Boca Raton, FL: CRC/Taylor \& Francis, 5th ed., 2007.

[23] A. Krings and J. Soulard, "Overview and Comparison of Iron Loss Models for Electrical Machines," Journal of Electrical Engineering, vol. 10, no. 3, pp. 162-169, 2010.

[24] M. Markovic and Y. Perriard, "Simplified Design Methodology for a Slotless Brushless DC Motor," IEEE Transactions on Magnetics, vol. 42, pp. 3842-3846, Dec. 2006.

[25] Z. Zhu, K. Ng, N. Schofield, and D. Howe, "Improved analytical modelling of rotor eddy current loss in brushless machines equipped with surface-mounted permanent magnets," IEEE Proceedings - Electric Power Applications, vol. 151, no. 6, p. 641, 2004.

[26] Jiabin Wang, K. Atallah, R. Chin, W. M. Arshad, and H. Lendenmann, "Rotor Eddy-Current Loss in Permanent-Magnet Brushless AC Machines," IEEE Transactions on Magnetics, vol. 46, pp. 2701-2707, July 2010.

[27] G. Burnand, D. M. Araujo, and Y. Perriard, "Very-high-speed permanent magnet motors: Mechanical rotor stresses analytical model," in IEEE International Electric Machines and Drives Conference (IEMDC), pp. 1-7, IEEE, May 2017.

[28] Y. Ishida and T. Yamamoto, Linear and nonlinear rotordynamics: a modern treatment with applications. Weinheim: Wiley-VCH, 2nd enlarged and improved ed., 2012. OCLC: ocn822958263. 